\title{
Front Matter: Volume 9142
}

, "Front Matter: Volume 9142," Proc. SPIE 9142, Selected Papers from Conferences of the Photoelectronic Technology Committee of the Chinese Society of Astronautics: Optical Imaging, Remote Sensing, and Laser-Matter Interaction 2013, 914201 (21 February 2014); doi: 10.1117/12.2060224

Event: Selected Proceedings of the Photoelectronic Technology Committee Conferences held July-December 2013, 2013, SuZhou, China 


\title{
Selected Papers from Conferences of the Photoelectronic Technology Committee of the Chinese Society of Astronautics
}

\section{Optical Imaging, Remote Sensing, and Laser-Matter Interaction 2013}

\author{
Jorge Ojeda-Castaneda, Shensheng Han, Ping Jia, Jiancheng Fang, Dianyuan Fan, \\ Liejia Qian, Yuqiu Gu, Xueqing Yan \\ Editors
}

\section{0-29 October 2013 \\ SuZhou, China}

International Conference on Frontiers in Optical Imaging Technology and Application

Sponsored by

Photoelectronic Technology Professional Committee, Chinese Society of Astronautics • Education and Training Department, China Ordnance Society

\section{Cooperating Organizations}

Changchun Institute of Optics, Fine Mechanics and Physics • Shanghai Institute of Optics and Fine Mechanics • State Key Laboratory of Transient Optics and Photonics Xi'an Institute of Optics and Precision Mechanics, CAS • Academy of Opto-Electronics, CAS • Shanghai Advanced Research Institute, CAS • Beijing Institute of Technology • Changchun University of Science and Technology • Institute of Modern Optical Technologies, Soochow University • School of Physics and Optoelectronic Engineering, Xidian University

\section{International Seminar on Aerial Optical Remote Sensing Technology and Application \\ Sponsored by \\ Photoelectronic Technology Committee, China Society of Astronautics}

\section{Cooperating Organizations}

Changchun Institute of Optics, Fine Mechanics and Physics, CAS • Shanghai Institute of Technical Physics, CAS • Anhui Institute of Optics and Fine Mechanics, CAS • The Institute of Optics and Electronics, CAS • China Aviation Industry Corporation Luoyang Institute of electro-optical devices • Beihang University • Institute of Modern Optical Technologies, Soochow University • MOES Education Ministry Key Laboratory, Tianjin University

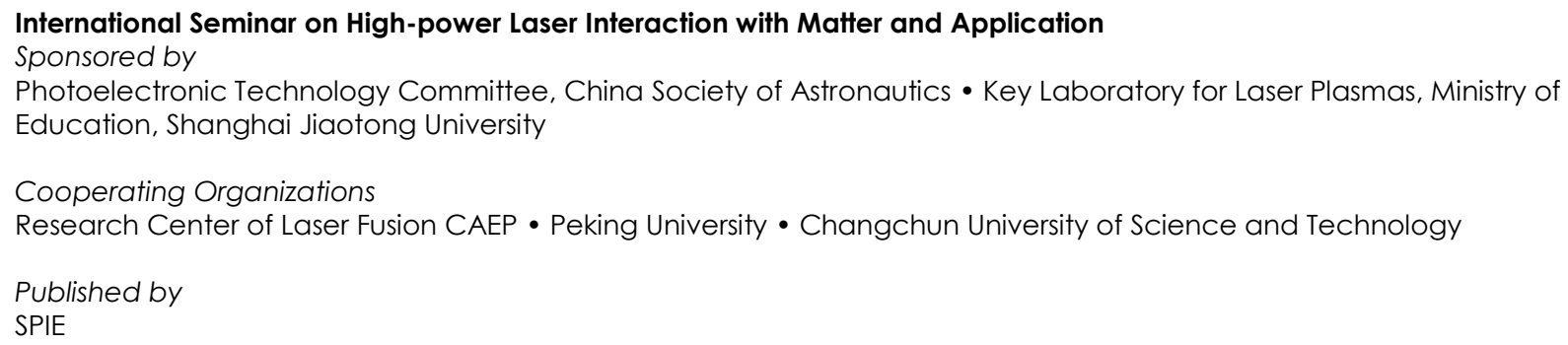

Volume 9142 
The papers included in this volume were part of the technical conference cited on the cover and title page. Papers were selected and subject to review by the editors and conference program committee. Some conference presentations may not be available for publication. The papers published in these proceedings reflect the work and thoughts of the authors and are published herein as submitted. The publisher is not responsible for the validity of the information or for any outcomes resulting from reliance thereon.

Please use the following format to cite material from this book:

Author(s), "Title of Paper," in

Selected Papers from Conferences of the Photoelectronic Technology Committee of the Chinese Society of Astronautics: Optical Imaging, Remote Sensing, and Laser-Matter Interaction 2013, edited by Jorge Ojeda-Castaneda, Shensheng Han, Ping Jia, Jiancheng Fang, Dianyuan Fan, Liejia Qian, Yuqiu Gu, Xueqing Yan, Proceedings of SPIE Vol. 9142 (SPIE, Bellingham, WA, 2014) Article CID Number.

ISSN: 0277-786X

ISBN: 9781628410938

Published by

SPIE

P.O. Box 10, Bellingham, Washington 98227-0010 USA

Telephone +1 3606763290 (Pacific Time) · Fax +1 3606471445

SPIE.org

Copyright (C) 2014, Society of Photo-Optical Instrumentation Engineers.

Copying of material in this book for internal or personal use, or for the internal or personal use of specific clients, beyond the fair use provisions granted by the U.S. Copyright Law is authorized by SPIE subject to payment of copying fees. The Transactional Reporting Service base fee for this volume is $\$ 18.00$ per article (or portion thereof), which should be paid directly to the Copyright Clearance Center (CCC), 222 Rosewood Drive, Danvers, MA 01923. Payment may also be made electronically through CCC Online at copyright.com. Other copying for republication, resale, advertising or promotion, or any form of systematic or multiple reproduction of any material in this book is prohibited except with permission in writing from the publisher. The CCC fee code is 0277-786X/14/\$18.00.

Printed in the United States of America.

Publication of record for individual papers is online in the SPIE Digital Library.

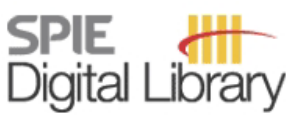

SPIEDigitallibrary.org

Paper Numbering: Proceedings of SPIE follow an e-First publication model, with papers published first online and then in print and on CD-ROM. Papers are published as they are submitted and meet publication criteria. A unique, consistent, permanent citation identifier (CID) number is assigned to each article at the time of the first publication. Utilization of CIDs allows articles to be fully citable as soon as they are published online, and connects the same identifier to all online, print, and electronic versions of the publication. SPIE uses a six-digit CID article numbering system in which:

- The first four digits correspond to the SPIE volume number.

- The last two digits indicate publication order within the volume using a Base 36 numbering system employing both numerals and letters. These two-number sets start with 00, 01, 02, 03, 04, 05, 06, 07, 08, 09, OA, OB ... 0Z, followed by 10-1Z, 20-2Z, etc.

The CID Number appears on each page of the manuscript. The complete citation is used on the first page, and an abbreviated version on subsequent pages. Numbers in the index correspond to the last two digits of the six-digit CID Number. 


\section{Contents}

xi Conference Committees

\section{Part One}

INTERNATIONAL CONFERENCE ON FRONTIERS IN OPTICAL IMAGING TECHNOLOGY AND APPLICATION

914202 Room temperature InGaAs hot electron detector for THz/subTHz regions [9142-5] J. Tong, J. Huang, Z. Huang, J. Chu, Shanghai Institute of Technical Physics (China)

914203 Biological detecting and imaging technology based on guided-mode resonance effect [9142-7]

Z. Wang, Q. Wang, D. Zhang, Q. Tang, S. Han, L. Ding, Univ. of Shanghai for Science and Technology (China)

914204 Characteristic research and linearity measurement of photodetectors [9142-8]

H. Hui, L. Yang, X. Ouyang, G. Li, H. Lu, Y. Guo, X. Jiang, B. Zhu, Z. Lin, Shanghai Institute of Optics and Fine Mechanics (China)

914205 Detection of small targets against complex sky background based on bidirectional SVD decomposition temporal filters [9142-9]

W. Hou, H. Liu, X. Liu, Z. Lei, National Univ. of Defense Technology (China)

914206 Detection of small target using recursive higher order statistics [9142-12]

W. Hou, National Univ. of Defense Technology (China); H. Sun, Army Aviation Institute of the Chinese Peoples (China); Z. Lei, National Univ. of Defense Technology (China)

914207 The small target detection based on maximum likelihood estimation and spot detection operator [9142-15]

W. Hou, G. Long, Z. Lei, J. Dong, National Univ. of Defense Technology (China)

914208 An infrared polarization image fusion algorithm based on oriented Laplacian pyramid [9142-21]

Z. Yue, Shanghai Institute of Technical Physics (China); F.-M. Li, Key Lab. of Infrared System Detection and Imaging Technology (China)

914209 Virtual ghost imaging with partially coherent hyperbolic cosine Gaussian beam through turbulence [9142-22]

X. Yang, Y. Zhang, L. XU, C. Jin, Q. Xin, Y. Zhao, Harbin Institute of Technology (China)

9142 0A Laser interfering profilometer for micro-ball whole surface measurement [9142-23]

B. Lu, J. Zhang, B. Liu, H. Sun, G. Liu, Harbin Institute of Technology (China)

9142 OB Quantum holography based on second-order correlation measurement [9142-24]

L. Gao, K. Kang, H. Lin, Z. Zheng, China Univ. of Geosciences (China) 
9142 OC An advanced time-domain projection-based registration scene based non-uniformity correction technology and the detailed hardware realization [9142-28]

N. Liu, Nanjing Xiaozhuang Univ. (China); Q. Chen, Nanjing Univ. of Science and Technology (China); H. Qiu, Nanjing Institute of Technology (China)

9142 OD Central obscuration effects on optical synthetic aperture imaging [9142-29]

$X$. Wang, Changchun Institute of Optics, Fine Mechanics and Physics (China) and Univ. of Chinese Academy of Sciences (China); X. Luo, L. Zheng, X. Zhang, Changchun Institute of Optics, Fine Mechanics and Physics (China)

9142 OE Computer-generated integral imaging system based on straight line characteristics [9142-30]

I. Dumchykov, Y. Piao, Changchun Univ. of Science and Technology (China)

9142 OF Eliminate background interference from latent fingerprints using ultraviolet multispectral imaging [9142-32]

W. Huang, X. XU, G. Wang, Institute of Forensic Science (China)

$91420 \mathrm{G}$ Fiber-coupled high power laser diode by wavelength multiplexing [9142-38]

Y. Ding, Y. Zou, L. Jin, H. Chen, X. Ma, Changchun Univ. of Science and Technology (China)

$9142 \mathrm{OH} \quad$ Integral imaging reconstruction by sampling elemental images [9142-39]

Y. Wang, Y. Piao, Changchun Univ. of Science and Technology (China)

9142 Ol Conceptual design of a rotating parallel-mirror-pair interferometer [9142-40]

Q. Cai, Univ. of Science and Technology of China (China); B. Xiangli, Univ. of Science and Technology of China (China) and Academy of Opto-Electronics (China); Q. Fu, L. Qian,

Y. Li, Z. Tan, Academy of Opto-Electronics (China)

9142 0J Study and application of body shape recognition based on depth image [9142-42]

Y. Han, J. Qin, Y. Li, J. Tao, Q. Fei, Univ. of Science and Technology of China (China)

9142 OK The progress of sub-pixel imaging methods [9142-45]

H. Wang, Xi'an Institute of Optics and Precision Mechanics (China) and Northwestern Polytechnical Univ. (China); D. Wen, Xi'an Institute of Optics and Precision Mechanics (China)

$9142 \mathrm{OL} \quad$ Lensless ghost imaging based on mathematical simulation and experimental simulation [9142-50]

Y. Liu, B. Wang, Y. Zhao, J. Dong, Science and Technology on Electro-optical Information Security Control Lab. (China)

$91420 \mathrm{M}$ Noise model and simulation analysis of the low noise pre-amplifier of CCD camera [9142-51]

Z. Chen, Y. Qiu, Y. Wen, B. Jiang, D. Yao, Xi'an Institute of Optics and Precision Mechanics (China)

9142 ON Image registration and noise removed for infrared subpixel-shifted images [9142-53] J. Bai, C. Zhao, The 28th Research Institute of China Electronics Technology Group Corp. (China); X. Wang, Nanjing Univ. of Science and Technology (China) 
$914200 \quad$ Numerical modeling on carbon fiber composite material in Gaussian beam laser based on ANSYS [9142-56]

J. Luo, S. Hou, J. Xu, W. Yang, Y. Zhao, Xi'an Research Institute of High-Tech (China)

9142 OP Phase correction of image plane in holographic microscopy with equal-step phase shift [9142-57]

H. Zhao, H. Zhou, F. Tai, J. Gu, Soochow Univ. (China)

$91420 Q \quad$ Improved orthogonal subspace projection algorithm [9142-60]

J. Lv, Y. Piao, Changchun Univ. of Science and Technology (China)

9142 OR Analysis on temperature effect of typical structure of lens in vision measurement [9142-61] G. Jiang, National Univ. of Defense Technology (China); Z. Wu, Xi'an Shiyou Univ. (China); Z. Chao, Chongqing Communication College (China); S. Fu, National Univ. of Defense Technology (China)

9142 OS Off-axis focusing and imaging of scaled zone plates and anamorphic photon sieves [9142-66]

J. Zhang, L. Zhang, Z. Jiao, Y. Zhang, Shanghai Institute of Optics and Fine Mechanics (China)

9142 0T Real-time tracking imaging measurement of low stretched trajectory [9142-70]

H. Wu, S. Zhang, P. Liu, W. Zhang, W. Wang, Ordnance Test Ctr. (China)

9142 OU 3D real-time measurement system of seam with laser [9142-71]

M. Huang, J. Huang, Beijing Institute of Petrochemical Technology (China)

9142 OV Algorithm selective method of infrared/visual image fusion system based on air humidity [9142-77]

B. Sun, J. Zhang, B. Chang, C. Min, Y. Li, Nanjing Univ. of Science and Technology (China)

9142 OW Research on integral imaging acquisition technology based on depth information matching [9142-79]

B. Tang, Y. Piao, I. Dumchykov, Changchun Univ. of Science and Technology (China)

$91420 \mathrm{X} \quad$ Cloud and aerosol polarimetric imager [9142-80]

J. Zhang, J. Shao, C. Yan, Changchun Institute of Optics, Fine Mechanics and Physics (China)

9142 OY Analysis and solution of the key problems in drift data processing of launch rocket [9142-82]

S. Cui, J. Liu, S. Shen, G. Li, State Key Lab. of Astronautic Dynamics (China) and Xi'an Satellite Control Ctr. of China (China)

$91420 Z$ Research on compressive fusion by multiwavelet transform [9142-87]

S. Yang, Xi'an Univ. of Arts and Science (China) and Northwestern Polytechnical Univ.

(China); G. Wan, Northwestern Polytechnical Univ. (China); Y. Li, X. Zhao, Xi'an Univ. of Arts and Science (China); X. Chong, Emerson Network Power Ltd. (China) 
914210 Research on the trace detection of carbon dioxide gas and modulation parameter optimization based on the TDLAS technology [9142-90]

P. Zhao, Changchun Univ. of Science and Technology (China) and Jilin Normal Univ.

(China); J. Tao, C. YU, Y. Li, Changchun Univ. of Science and Technology (China)

914211 Progress in development of imaging polarimeter for Stokes parameter measurement [9142-94]

R. Xia, X. Wang, W. Jin, J. Liu, Beijing Institute of Technology (China)

914212 Coherent CdTe terahertz source for high-resolutional imaging [9142-95]

J. Huang, J. Tong, Z. Huang, J. Chu, Shanghai Institute of Technical Physics (China)

914213 Methods of foreign fiber detecting based on PCA analyzing of infrared spectral images [9142-97]

L. Tian, W. Fu, Zhongguancun Science Park Haidian Park Enterprise (China); J. Liu, H. Zhang,

J. Pan, Y. Wang, F. Tong, Beijing Daheng Image Vision Co. Ltd. (China)

914214 Wide spectral range imaging acousto-optic turnable filter used in outer space probe [9142-99]

Z. Zhang, The 26th Institute of China Electronics Technology Group Corp. (China); L. Wang, Daxian No. 3 Middle School (China); X. He, Y. Zhou, The 26th Institute of China Electronics Technology Group Corp. (China)

914215 An algorithm of rapid extraction star point and diffuse plaque in star image [9142-105] S. Wang, Y. Li, L. Du, Y. Fan, The Academy of Equipment (China)

914216 Design and implementation of range-gated underwater laser imaging system [9142-106] W. Ge, X. Zhang, Naval Univ. of Engineering (China)

\section{Part Two}

914217 Defects in undoped semi-insulating InP [9142-111]

Y. Chen, X. Guo, Mianyang Normal Univ. (China)

914218 Splash generation and evolvement in the laser ablation with liquid working substance [9142-113]

J. Ye, Y. Hong, N. Li, The Academy of Equipment (China)

914219 The simulation of natural low level light under lab's condition [9142-114]

W. Lin, J. Wang, X. Wang, Z. An, H. Jiang, Changchun Univ. of Science and Technology (China)

\section{INTERNATIONAL SEMINAR ON AERIAL OPTICAL REMOTE SENSING TECHNOLOGY AND APPLICATION}

9142 1A Endmember extraction algorithm for hyperspectral image based on PCA-SMACC [9142-11] C. Liu, J. Li, G. Wang, Science and Technology on Optical Radiation Lab. (China) 
9142 1B The acquisition of land cover information using three indexes and TM Image [9142-13] S. Li, Z. Wang, North Univ. of China (China); J. Yang, Ball State Univ. (United States);

Z. Wang, F. Wang, North Univ. of China (China)

$91421 \mathrm{C}$ The polarisation correction for space-borne grating spectrometers [9142-17] F. Zhao, Q. Sun, K. Chen, X. Zhu, S. Wang, G. Wang, X. Zheng, Z. Han, The 4lst Research Institute of China Electronics Technology Group Corp. (China)

9142 1D A method of using commercial virtual satellite image to check the pattern painting spot effect [9142-18]

Z. Wang, Q. Kang, Z. Shen, C. Cui, Logistic and Engineering Univ. (China)

9142 IE Electronics design of the airborne stabilized platform attitude acquisition module [9142-25] J. Xu, G. Wei, The 26th Institute of China Electronics Technology Group Corp. (China); Y. Cheng, Xin Jiang Astronomical Observatory (China) and Key Lab. of Radio Astronomy (China); B. Li, The 26th Institute of China Electronics Technology Group Corp. (China); H. Bu, Shanghai Institute of Technical Physics (China); H. Wang, Z. Zhang, The 26th Institute of China Electronics Technology Group Corp. (China); X. Li, Chongqing Normal Univ. (China)

$91421 \mathrm{~F}$ The research and application of medium resolution remote sensing images in the city information extraction [9142-31]

F. Wang, North Univ. of China (China); J. Yang, North Univ. of China (China) and Ball State Univ. (United States); S. Li, Z. Wang, North Univ. of China (China)

$91421 \mathrm{G}$ Land use changes and its impact on land surface temperature of Yancheng City from 2000 to 2009 analysis [9142-33]

$X$. Wang, Pearl River Water Resources Scientific Research Institute (China)

$9142 \mathrm{lH} \quad$ Error correction of photoelectric rotary and angle encoder [9142-34]

L. Zhou, Xi'an Institute of Optics and Precision Mechanics (China) and Univ. of Chinese Academy of Sciences (China); W. She, J. Huang, Xi'an Institute of Optics and Precision Mechanics (China)

914211 The precision analysis of continuous zoom lens in airborne electro-optical pod [9142-35] X. Yang, D. Li, J. Han, Xi'an Institute of Optics and Precision Mechanics (China); Q. Dong, $X i^{\prime}$ an Institute of Optics and Precision Mechanics (China) and Univ. of Chinese Academy of Sciences (China); W. Huang, Y. Wei, Xi'an Institute of Optics and Precision Mechanics (China)

$91421 \mathrm{~J} \quad$ Target location in aerial image by fast NCC [9142-41]

J. Dong, X. Yang, W. Hou, National Univ. of Defense Technology (China)

9142 1K SAR image registration based on SIFT and MSA [9142-43]

Z. Yi, X. Zhang, X. MU, K. Wang, J. Song, Xi'an Research Institute of High-Tech (China)

$91421 \mathrm{~L} \quad$ Polarization measurement through combination polarizers [9142-44]

Y. Bai, L. Li, Z. He, Y. Liu, C. Ma, Heilongjiang Institute of Technology (China); G. Shi, Harbin Institute of Technology (China); L. Liu, Harbin Engineering Univ. (China)

$91421 \mathrm{M}$ Effects of stitching pattern on diffractive telescope image quality [9142-62]

Z. Zhang, Y. Xie, F. Kang, Y. Wang, Xi'an Institute of Optics and Precision Mechanics (China) 
$91421 \mathrm{~N}$ Analysis the application of several denoising algorithm in the astronomical image denoising [9142-73]

C. Jiang, Z. Geng, Information Engineering Univ. (China); Y. Bao, Information Engineering Univ. (China) and Troops 66393 (China); X. Wei, Information Engineering Univ. (China); Y. Pan, Troops 61175 (China)

914210 Yellow River Estuary typical wetlands classification based on hyperspectral derivative transformation [9142-74]

X. Wang, Dalian Maritime Univ. (China), Qingdao Univ. (China), and First Institute of Oceanography (China); J. Zhang, Dalian Maritime Univ. (China) and First Institute of Oceanography (China); G. Ren, Y. Ma, First Institute of Oceanography (China)

$91421 \mathrm{P} \quad$ Applied low dimension linear manifold in hyperspectral imagery anomaly detection [9142-76]

Z. Li, L. Wang, S. Zheng, National Univ. of Defense Technology (China)

$91421 Q \quad$ Infrared and visible sequential images registration based on the motion characteristics [9142-83]

Z. Xu, Z. Huang, Z. Chi, Institute of Digital Engineering (China)

9142 IR Study of sensing properties and contrastive analysis of metal coating optical fiber grating [9142-85]

J. Wang, Nanjing Univ. (China) and Shandong Univ. (China); N. Wang, Shandong Univ.

(China); B. Shi, Nanjing Univ. (China); Q. Sui, C. Guan, Shandong Univ. (China); G. Wei, S. Li, Nanjing Univ. (China)

9142 is Research on compressive fusion for remote sensing images [9142-86]

S. Yang, Xi'an Univ. of Arts and Science (China); G. Wan, Northwestern Polytechnical Univ. (China); Y. Li, X. Zhao, Xi'an Univ. of Arts and Science (China); X. Chong, Emerson Network Power Ltd. (China)

9142 IT The remote sensing image matching based on SURF algorithm [9142-89]

Y. Hu, B. Li, L. Shi, Tianjin Jinhang Institute of Technical Physics (China)

$91421 U$ FPGA implementation of real-time digital image stabilization [9142-91]

G. Li, Changchun Institute of Optics, Fine Mechanics and Physics (China)

$91421 \mathrm{~V}$ Laser image denoising technique based on multi-fractal theory [9142-92]

L. Du, H. Sun, W. Tian, S. Wang, The Academy of Equipment (China)

9142 IW Research on distribution characteristic of sky background luminance [9142-96]

W. Liu, X. Qiang, Y. Wang, Northwest Institute of Nuclear Technology (China)

$91421 Y \quad$ Micro biochemical sensor based on SOI planar optical waveguide [9142-103]

Y. Du, Y. Dong, Tsinghua Univ. (China)

914212 Study on full-polarization hyperspectral imaging technology [9142-104]

X. Wei, Q. Zhou, T. Zhong, Y. Li, Zhejiang Univ. (China)

914220 Measurement and analysis of atmospheric optics parameters In northwest ward [9142-107] G. Sun, N. Weng, Q. Liu, C. Zhang, M. Cheng, Anhui Institute of Optics and Fine Mechanics (China) 
914221 The analysis of distribution of meteorological over China in astronomical site selection [9142-108]

C. Zhang, Anhui Institute of Optics and Fine Mechanics (China) and Graduate Univ. of Chinese Academy of Sciences (China); N. Weng, Anhui Institute of Optics and Fine Mechanics (China) and Univ. of Science and Technology of China (China)

914222 Development of a digital solar simulator based on full-bridge converter [9142-109] C. Liu, J. Feng, Z. Liu, W. Tong, Y. Ji, Hefei Univ. of Technology (China)

914223 Scintillation analysis for multiple uplink Gaussian beams in the presence of beam wander [9142-1 10] W. Wu, National Univ. of Defense Technology (China), Anhui Institute of Optics and Fine Mechanics (China), and Graduate Univ. of Chinese Academy of Sciences (China); Y. Ning, National Univ. of Defense Technology (China); P. Zhang, X. Feng, C. Qiao, Anhui Institute of Optics and Fine Mechanics (China)

914224 The research of cat-eye target laser active detection system performance [9142-112] Z. Hou, Y. Li, S. Wang, The Academy of Equipment (China)

\section{INTERNATIONAL SEMINAR ON HIGH-POWER LASER INTERACTION WITH MATTER AND APPLICATION}

914225 Infrared smoke field testing system based on computer calculation [9142-6] R. Tang, S. Li, Beijing Institute of Technology (China); Y. Cui, Troops 73921 (China); N. Dong, Troops 57015 (China); T. Zhang, Z. Zhou, Beijing Institute of Technology (China)

914226 Influence of ellipticity in coherent soft x-ray harmonic generation from atoms and molecules [9142-26] Y. Xia, F. Lu, S. Zhang, D. Chen, Harbin Institute of Technology (China)

914227 Theoretical investigation of output features of a diode-pumped rubidium vapor laser [9142-46] Y. Wang, H. Cai, W. Zhang, L. Xue, H. Wang, J. Han, Southwest Institute of Technical Physics (China)

914228 Simulation and analysis of scattering characteristics for Gaussian beam and plane beam [9142-47]

L. Wang, Y. Bi, X.-K. Zhao, J.-J. Wang, Xi'an Research Institute of High-Tech (China)

914229 Research on rail surface non-touch statistic and dynamic measuring technique [9142-49] Z. Bi, Tongji Univ. (China); L. Wang, Xi'an Research Institute of High-Tech (China); A. Wang, Xi'an BEI TE Development of Science and Technology Co., Ltd. (China)

9142 2A BPM analysis of all-optical fiber interferometric sensor based on a U-shape microcavity [9142-58] H. Wu, L. Yuan, S. Wang, Beijing Institute of Technology (China); L. Zhao, The 3rd Research Institute of China Electronics Technology Group Corp. (China); Z. Cao, Beijing Institute of Technology (China) 
9142 2B The compression of ASE pulses using optical breakdown clipping in liquid [9142-69] P. Du, Z. Lu, D. Lin, Harbin Institute of Technology (China)

$91422 \mathrm{C}$ The collapse of fields and density disturbance in laser-produced critical density plasma [9142-78]

S.-Y. Zhou, Jiangxi Science and Technology Normal Univ. (China)

9142 2D Solid state laser ablation effect on laser-proof composite coating applied in aerospace material [9142-84]

J. Li, Beijing Institute of Aeronautical Materials (China); Y. Zheng, J. Luo, Z. Liu, S. Chen, Chengdu Fine Optical Engineering Research Ctr. (China); Y. Zhang, Z. Wang, Beijing Institute of Aeronautical Materials (China)

$91422 \mathrm{E} \quad$ A novel method for detecting melamine in pure milk [9142-88]

L. Wang, B. Peng, X. Jiang, Q. Shi, Zhejiang Normal Univ. (China)

$91422 \mathrm{~F} \quad$ Backscattered signal modulation and emitting module design for a cloud lidar [9142-93] $X$. Shu, Bureau of Army Aviation (China); Z. Chen, Anhui Institute of Optics and Fine Mechanics (China); X. Lian, H. Jin, Bureau of Army Aviation (China); X. Zhang, Beihang Univ. (China)

Author Index 


\section{Conference Committees}

\section{International Conference on Frontiers in Optical Imaging Technology and Application}

Conference Chairs

Jorge Ojeda-Castaneda, Universidad de Guanajuato (Mexico)

Wei Zhao, Xi'an Institute of Optics and Precision Mechanics of Chinese Academy of Sciences (China)

Libin Xiang, Academy of Opto-Electronics, Chinese Academy of Sciences (China)

Chairs of Academic Committee

Shensheng Han, Shanghai Institute of Optics and Fine Mechanics, Chinese Academy of Sciences (China)

Zhongyang Wang, Academy of Opto-Electronics, Chinese Academy of Sciences (China)

Lei Yan, Peking University (China)

Vice Chairs of Academic Committee

Lakshminarayan Hazra, University of Calcutta (India)

Vasilis Nłziachristos, Technische Universität München (Germany) and Institut für Biomedizinische Bildgebung (Germany)

Josué Álvarez-Borrego, El Centro de Investigación Científica y de Educación Superior de Ensenada (Mexico)

Yoon-Ho Kim, Pohang University of Science and Technology (Korea, Republic of)

Baoli Yao, Xi'an Institute of Optics and Precision Mechanics of Chinese Academy of Sciences (China)

Jin Lu, Tianjin Jianhang Institute of Technical Physics (China)

Weimin Shen, Soochow University (China)

Qiang Sun, Changchun Institute of Optics, Fine Mechanics and Physics, Chinese Academy of Sciences (China)

Tingfa Xu, Beijing Institute of Technology (China)

Yuegang Fu, Changchun University of Science and Technology (China)

Fuli Li, Xi'an Jiaotong University (China)

Xiaopeng Shao, Xidian University (China) 


\title{
International Seminar on Aerial Optical Remote Sensing Technology and Application
}

\author{
Conference Chairs
}

Jorge Ojeda-Castaneda, Universidad de Guanajuato (Mexico)

Jiancheng Fang, Beihang University (China)

Ping Jia, Changchun Institute of Optics, Fine Mechanics and Physics, Chinese Academy of Sciences (China)

Conference Cochairs

Gianluca Valentini, Politecnico di Milano (Italy)

Josué Álvarez-Borrego, El Centro de Investigación Científica y de

Educación Superior de Ensenada (Mexico)

Jin Lu, Tianjin JinHang Institute of Technical Physics (China)

Lakshminarayan Hazra, University of Calcutta (India)

Ning Dai, Shanghai Institute of Technical Physics, Chinese Academy of Sciences (China)

Wilhelm Stork, Karlsruher Institut für Technologie (Germany)

Weimin Shen, Soochow University (China)

Xiangjun Wang, MOES Education Ministry Key Laboratory, Tianjin University (China)

Yi Yang, Luoyang Institute of Electro-optical Devices, China Aviation Industry Corporation (China)

\section{International Seminar on High-power Laser Interaction with Matter and Application}

\section{Conference Chair}

Dianyuan Fan, Shanghai Institute of Optics and Fine Mechanics, Chinese Academy of Sciences (China)

\section{Conference Cochairs}

Liejia Qian, Shanghai Jiaotong University (China)

Yuqiu Gu, Research Center of Laser Fusion, China Academy of Engineering Physics (China)

Xueqing Yan, Peking University (China)

Guangyong Jin, Changchun University of Science and Technology (China)

\section{Program Committee}

David Neely, Rutherford Appleton Laboratory (United Kingdom)

Thomas Cowan, Helmholtz-Zentrum Dresden-Rossendorf (Germany)

John Seely, National Institute of Standards and Technology (United States) 
Anatoly Faenov, Joint Institute for High Temperature, Russian Academy of Science (Russian Federation)

Wenjun Ma, Ludwig-Maximilians Universität (Germany)

Jianhui Bin, Ludwig-Maximilians Universität (Germany)

Jianqiu Xu, Shanghai Jiaotong University (China)

Liming Chen, The Institute of Physics, Chinese Academy of Sciences (China)

Jin Guo, Changchun Institute of Optics, Fine Mechanics and Physics, Chinese Academy of Sciences (China) 